\title{
A REVIEW OF THE SUITABILITY OF USING ECO-EFFICIENCY PRINCIPLES IN MANAGING ENVIRONMENTAL IMPACTS OF THE PACKAGED WATER INDUSTRY IN GHANA
}

\author{
Ebo Tawiah Quarteyํㅗ Samuel Antwi Darkwah²
}

\begin{abstract}
${ }^{1}$ Department of Regional and Business Economics, Faculty of Regional Development and International Studies, tř. Generála Píky 7, 61300 Brno, Czech Republic

${ }^{2}$ Department of Territorial Studies, Faculty of Regional Development and International Studies, tř. Generála Píky 7, 61300 Brno, Czech Republic
\end{abstract}

\begin{abstract}
QUARTEY EBO TAWIAH, DARKWAH SAMUEL ANTWI. 2018. A Review of the Suitability of Using Eco-efficiency Principles in Managing Environmental Impacts of the Packaged Water Industry in Ghana. Acta Universitatis Agriculturae et Silviculturae Mendelianae Brunensis, 66(4): 979-989.

The production and use of sachet water in Ghana has been consistently increasing, filling the gap of inadequate access to safe drinking water. Despite the obvious significant socio-economic impact of the packaged water industry in Ghana, the associated environmentalimpacts of the production and use cannot be overlooked. The aim of this paper is to analyze the prospects of eco-efficiency approach as a more sustainable means of production in the industry, leading towards the sustainable development agenda of the country. The methodology employed in this paper is desktop research with qualitative data collection and analysis, utilizing existing literature or secondary data. It was concluded that there are many good reasons for adopting an eco-efficiency in the packaged water industry, including reducing operating costs and improve profitability by reducing energy, water supply, and solid waste costs, reducing water wastage and contribute in developing solid waste minimization plans.

The significance of this paper is to increase the awareness of the effect of improper disposal of sachet waste on the Ghanaian environment and also seeks to inform the management of the many companies in the packaged water industry, stakeholders and consumers to be environmentally responsible, as their actions can help protect and improve the natural environment while improving the overall economy.
\end{abstract}

Keywords: eco-efficiency, environmental impact, Ghana, packaged water industry, sachet water, sustainable development

\section{INTRODUCTION}

Just like most of sub-Saharan Africa countries, the provision of safe drinking water to a greater portion of the populace continues to be a problem in Ghana. The responsibility of production, distribution, and conservation of water for public, domestic, commercial and industrial use in Ghana belongs to the Ghana Water Company Limited (GWCL) but population growth and the rapid pace of urbanization have outstripped the capabilities of GWCL to cope with the increasing demand for water for domestic, industry and commerce uses
(MWRWH, 2010). The current demand for water from both the urban and rural population outstrips current levels of water supply in the country. According to GWCL, the average water production is $871,496 \mathrm{~m}^{3}$ per day (192 million gallons per day) but the current water demand is estimated at 1,131 , $8181 \mathrm{~m}^{3}$ per day (249 million per day) (GWCL, n. d.). GWCL operates 88 urban water supply systems throughout the country with urban water supply coverage of about $77 \%$ (GWCL, n. d.), however, such reports by GWCL and organizations like WHO suggesting improvements in access to a safe source of water often masks the true drinking water 
coverage given the sporadic nature of urban water supply in Ghana. Recent literature (Mahama et al., 2014; Adjei, 2016) suggests access to drinking water in many urban areas falls short of such reports and estimates, where water is sometimes rationed to many consumers with only a few customers able to get 24-hour supply. This is also evident in low-income communities as seen elsewhere in sub-Saharan Africa (Hopewell and Graham, 2014).

Filling the service gap are private water vendors, who have become an important source of drinking water for the country. Even though tap water is said to be safe for drinking, its limited availability coupled with people's general mistrust of quality of tap water has led to the dependence on packaged water (Stoler et al., 2015). According to the 2010 Water and Sanitation Sector Performance Report, in $2008,12 \%$ of the total urban population and $1.1 \%$ of the rural population shifted from drinking tap water to packaged (bottled and sachet) water and the bulk of the packaged water consumed is sachet water, which is well patronized by people within the middle and lower classes due to perceptions of poor quality water from public supplies (GDHS, 2008; MWRWH, 2010). By 2014, 43.1\% of urban households (38\% urban population) and $11.8 \%$ of rural households ( $8 \%$ of the rural population) depended on bottled or sachet water as improved source of drinking water (GDHS, 2014). This widespread use of packaged water such as sachet water continues to stir controversy as it not only provides many jobs and improves access to potable drinking water, but there are unintended environmental consequences associated with it. Aside from the obvious environmental impacts of sachet water waste on the Ghanaian environments, there are other issues associated with the production process such as energy consumption, emission from transportation, water wastage and quality of sachet water. It is the impact of these unintended consequences that have prompted the writing of this paper, which will deal with the following objectives:

- Review the status of packaged water production, specifically sachet water and impact of its sales and use on the environment.

- Analyse the standards set by the regulatory agencies for the production of packaged water.

- Identifying some of the major factors that influence the social responsibility of sachet producers and recommend an eco-efficient framework for production which can have implications for the management of sachet water waste.

\section{MATERIALS AND METHODS}

Information gathering is the essential necessity for any research. This research paper was based on the qualitative data collection, review and analysis, utilizing existing literature or secondary data. According to Hoepfl (1997), "qualitative researchers seek illumination, understanding, and extrapolation to similar situations" and qualitative research is known as "real world" research (Endacott, 2005), because qualitative research uses a naturalistic approach to understand the phenomena and it tries to reveal the truth (Golafshani, 2003). Qualitative methods are used to describe, search or find out any phenomenon which does not explain or understand well so far (Strauss and Corbin, 1990) and according to Silverman (2010), it is suitable for describing the ideas under study and it is more critically astute and furthermore qualitative data can give much more information which cannot be obtained from statistical sampling techniques. The factors considered during the development of this research paper includes the overview of the packaged water industry production, the socio-economic impact of sachet water industry, environmental impact and the implication of the concept of eco-efficiency for SMEs with attention to sachet water. This involved searching and identifying the possible source of the necessary data, mainly from publications from journals in databases like SCOPUS, Web of Science and magazines, newspapers, websites, public records, reports, policies, action plans by relevant public bodies. Search words included Ghana, Sachet water, and sachet water production, the socio-economic impact of sachet water production, the environmental impact of sachet water production, eco-efficiency, and SMEs. Information gathered is analyzed and deductions made to arrive at a conclusion.

\section{The concept of Eco-efficiency and environmental management}

The concept of eco-efficiency was first introduced and discussed by two Swiss researchers Stefan Schaltegger and Andreas Sturm in 1990 (Schaltegger, 1996) and came about because of the need for instruments that can translate sustainable development into working targets (Eik, 1998).

Eco-efficiency is achieved by the delivery of competitively priced goods and services that satisfy human needs and bring the quality of life, while progressively reducing ecological impacts and resource intensity throughout the life-cycle to a level at least in line with the Earth's estimated carrying capacity. Mathematically, Eco-efficiency is measured as the ratio between the value of what has been produced (income, high-quality goods, and services, jobs, GDP etc) and the sum of the environmental life cycle impacts of the product or service:

\section{Eco efficiency $=\frac{\text { Value of products or service }}{\text { Sum of environmental life cycle impacts }}$}

Where the product or service can be a small or a large scale economic activity and eco-efficiency of such a product or service would be improved by increasing the value of the product and decreasing the environmental life cycle impacts (production, use, recycling/disposal) of the product or service. The European Environment Agency (EEA) defines it as "more welfare from less nature" and says 
it comes through decoupling resource use and pollutant release from economic development and overall welfare. It is a management philosophy that encourages business to search for environmental improvements that yield parallel economic benefits. It focuses on business opportunities and allows companies to become more environmentally responsible and more profitable. Eco-efficiency is a key business contribution to sustainable societies. In short, it is concerned with creating more value with less impact. There have been great advances in the application of eco-efficiency principles in the developed world. There is evidence of Industries in developed countries having considerable success in reducing pollution and emissions and eliminating hazardous materials from production processes. In the past, business viewed the environment and sustainable development as problems and risk factors but currently, they are opportunities (sources of efficiency improvement and growth). Eco-efficiency basically is about doing more with less, delivering more value while using fewer resources. Saving energy, for example, cuts costs while also reducing unwelcome outputs such as emissions. Not only does eco-efficiency improves a business' environmental performance, it also helps companies get in front of the market and regulatory trends, to reduce costs, to gain competitive advantage and to ensure long-term profitability and sustainability.

\section{Overview and impact of sachet water industry in Ghana}

The sachet water is locally referred to as "pure water". The water that is used to produce the sachet water is usually treated (filtered) from the tap (Ackah-Arthur, 2011; Stoler et al., 2012; Arku, 2016), surface water and underground water from dug wells or bore-holes (Grönwall and Oduro-Kwarteng, 2017). The sachet water producing industry is characterized by small and medium to large scale companies that package and machine-seal sachet water, with some, also offering bottled water to consumers. The small-scale companies produce between 15000 to 45000 sachets per day and usually, each sachet contains $500 \mathrm{ml}$ of water (Ackah-Arthur, 2011). The sachets are packaged in bags, each bag usually containing 30 sachets. These small-scale manufacturers have much smaller distribution coverage, most often distributing their products in and around the communities and towns where their factory is located (Ackah-Arthur, 2011). The medium to large-scale producers, on the other hand, do have the technology, resources, and adequate logistics support to produce both bottled and sachet water for more than one town and even may be able to cover a district or sometimes a municipality (Ackah-Arthur, 2011). The large-scale producers also have better technology, resources, and adequate logistics support to produce both bottle and sachet water for sale nationwide. Most of the medium and large-scale companies operate water packaging factories and depots in several towns and cities across Ghana and usually produce and supply over 5000 bags of sachet water per day (Ackah-Arthur, 2011). The producers usually sell only in bulk to distributors, resellers, and retailers, but sometimes directly to consumers, in the case of small-scale producers. Most of the medium and large-scale producers have their own distribution trucks which go around distributing the sachet water to known distributors and, in some cases, individuals can stop and buy directly from the trucks at factory (wholesale) prices at vantage points. The distributors refer to those who buy sachet water in bulk from the producers and sell them to other entrepreneurs rather than the consumers. Resellers refer to those who also sell the sachet water in bulk but to the end consumers, while retailers sell to street hawkers who sell individual sachets to the consumers. Most of the street hawkers normally sell the sachet water in traffic, at roadsides, and at lorry stations. Producers and distributors/retailers/vendors of sachet water usually make close to $100 \%$ (sometimes even more) profit on their sales (Okogia, 2007; Ackah-Arthur, 2011). This and due to the relatively low start-up capital required, has led to a proliferation of sachet water producing companies all across the country.

There are also associations and clubs like the National Association of Sachet Water Producers (NASWAP), now National Association of Sachet and Packaged Water Producers (NASPAAP) formed and registered as a formal body in 1999 with membership offered to companies registered under companies' code, 1963 (Act 179) to engage in the commercial packing of water. Such organizations were formed as the result of the persistent calls on sachet water producers to improve the quality of water being offered for sale to the public. The NASWAP is recognized at all levels in the Ghanaian society and has a strong collaboration with the Food and Drugs Board (FDB), Ghana Standards Board (GSB) and metropolitan/urban/local authorities. The National Association of Sachet and Packaged Water Producers aims mainly at the introduction of excellent and ethical business practices in the industry. Its constitution insists that applicants regularized their standing with the regulatory bodies mentioned prior to being offered membership. It is estimated that there are over 300 members with females outnumbering males and the funding for the association comes from membership dues and levies decided upon in times of need or problems.

\section{RESULTS AND DISCUSSION}

\section{Regulation and monitoring of sachet water production}

The production and sale of sachet water are regulated and certified by the Ghana Standards Authority (GSA) and Food and Drugs Authority (FDA) (Stoler et al., 2012; Dzodzomenyo et al., 2017). These institutions are mandated to protect 
consumers against inferior products. The GSA develops and regulates standards for a variety of products from foods, drinks, and medicines to electrical and other engineered products but the FDB only regulates and certifies foods, drinks, drugs, cosmetics, and other products that may have health implications for the public (GSA, 2005; Ackah-Arthur, 2011). The GSA is responsible for two standards related to how water is to be collected under conditions that guarantee their purity and a prescribed chemical composition for production (a more stringent standard covering production of natural mineral water 'obtained directly from natural or drilled sources from underground water-bearing strata) and a second standard that covers other forms of packaged water, notably packaged tap water but also groundwater that may not meet mineral water requirements (GSA, 2005; GSA, 2009 and Dzodzomenyo et al., 2017). GSA certified products bear the "Mark of Conformity", also called the "Certification Mark" or the "Quality Mark" (which generally serves as an assurance of quality in locally produced goods in Ghana) after quality control and inspection by the GSA. The FDA enforces its own standards and those of the GSA and mainly responsible for product registration to these standards, which is mandatory since 2012 (Dzodzomenyo et al., 2017). The FDB is the main monitoring agency with oversight over the sachet water industry and specifies guidelines for the establishment of sachet water factories. In 2016, the FDA reported that 1238 sachet water producers were officially registered nationwide (Ghanaweb, 2016), with approximately 500 operating in the capital, Accra (Morinville, 2017) However, it is believed that numbers of unregistered companies locally known as 'abalowe' operating on the blind side of the regulatory authorities is quite high (Dzodzomenyo et al., 2017) and most them are specially located in the rural areas (Bonsu, 2013).

\section{Socio-Economic Impact of the Sachet Water Production}

Safe drinking water remains inaccessible to over a billion people in the world and the hourly toll from biological contamination of drinking water is 200 deaths of children below the age of five years (Gadgil, 2008). A reliable supply of clean wholesome water is therefore crucial in promoting healthy living amongst inhabitants of a well-defined geographical region (Mustapha and Adam, 1991). In Ghana, the supply of piped water is inadequate (both in quantity and quality) in both urban and rural areas. This inadequacy is due to production limitations and poor water resource management. The Ghana Water Company Limited (GWCL), the main state institution for production and distribution of piped water faces serious constraints in meeting the challenge of providing adequate water for all rural and urban residents. Due to the high demand at any given time, the Ghana Water Company Ltd. (GWCL) is forced to implements a rationing program as they are not able to meet this demand. This rationing is influenced by geography (those living near large capacity water mains and valves may have better access) and by income (the wealthy generally enjoy the best maintenance and service levels) (Stoler et al., 2013).

Filling this gap of the state's inability to provide regular drinking water to a greater number of citizens is the packaged water industry. Packaged water (refill, bottled, or sachet water) has become an important element of water security in many low and middle-income countries, owing to poor reliability and lack of piped water infrastructure (Vedachalam et al., 2017). These packaged water producers, especially the sachet water producers have unofficially become critical for the socio-economic development of people in the low and middle class in the country. Several communities, especially low-income communities, where pipe water from the Ghana Water Company Limited (GWCL) does not reach or where the service is not consistent, benefits from the sachet water industry as it provides easy access to potable drinking water. Thanks to the $500 \mathrm{~mL}$ sachet water, many Ghanaians are now able to access, and drink packaged water at the price of 20 Ghana pesewas (.05 Euros). As an economic activity, the business of producing, distribution, retailing and selling sachet water also generates a lot of employment for many low and middle-class Ghanaians. Due to the low capital required to start up a sachet water production or distribution business, the sector has been growing. The industry is believed to be the biggest sector for small and medium scale enterprises (SMEs) for the Ghanaian economy (Suleiman, 2014). Even though there aren't any official data on the numbers of people in the packaged water industry, however, according to Stoler et al. (2013), there are groups such as the Association of Ghana Industries, National Association of Sachet Water Producers, Accra Ice and Pure Water Association, and the Ghana Plastic Manufacturers Association had made attempt to quantify the economic impact of their activities on the Ghanaian economy and these industry groups collectively estimate that there are over 2,700 sachet producers $(99 \%$ of whom are local Ghanaian businesses).

In 2014, a report by the online version of the Ghanaian newspaper, the Daily Graphic, estimated that within a period of 5 years, the industry generated 4 million jobs and the 10 major players in the sachet water business operate in the Accra and Tema region and employ more than two million people directly and indirectly (Suleiman, 2014). A study conducted by Kusi et al. (2015) in the Cape Coast Metropolis, where they sampled 103 and 24 SME sachet water distributors and producers respectively, showed that the drive for income generation and job creation were the main motivating factors that pushed respondents to do business in the commercial drinking water industry and most of their respondents self-financed 
their business. Also, according to Addei (2016), about 10,000 youth are employed in the sachet water production, plastic waste collection, and recycling business sectors. Therefore, Sachet water production and associated businesses is a viable business sector that can help to reduce the poverty level in Ghana as access to safe drinking water not only is key to sustainable development but essential to quality health and poverty reduction. The socioeconomic impacts of the sachet water production and its associated businesses include providing employment opportunities, income generation thereby increasing the standards of living and provides most Ghanaians easy access to potable drinking water.

\section{Health and Environmental impact of the Sachet Water Production}

Environmental quality is one of the greatest legacies that the current generation can pass on to the future generation. Even though sachet water has quickly become the primary source of drinking water for many Ghanaians who cannot depend on other, less reliable sources, its production and use also come with associated health and environmental risks (Stoler, 2013; Stoler et al., 2013).

The industry impacts on the Ghanaian environment in many areas of their activities but the most noticeable is environmental impact created be post-consumption of sachet water. The most volatile issue concerning sachet water use in Ghana and most other sachet consuming countries is the accumulation of sachet waste. An estimated 270 tons of plastic waste is generated every day, with $85 \%$ coming from non-biodegradable plastic bags (including sachets) containing drinking water and ice cream (IRIN, 2004; Stoler et al., 2012; Suleiman, 2014). The plastic used for making the package for sachet water is high-density polyethylene (HDPE), which is slightly opaque, has a higher tensile strength (more difficult to elongate), and can withstand higher temperatures. Even though there are no official data on the amounts of sachet waste generated in Ghana, Fobil (2000) estimates that seventy percent of plastic wastes generated is the LDPE and sachet HDPE film and Wardrop et al (2017) were able to estimate that 14000 tonnes of HDPE primary packaging are generated annually in Ghana from sachet use. Despite the popularity of sachet products, infrastructure for recycling or disposal is very limited. About 120 metric tons of waste is recycled daily in Ghana, with empty plastic water sachets accounting for about $40 \%$ of this figure (Addei, 2016). The inadequate collection coupled with the overall attitude of people has resulted in sachet wastes typically ending up being thrown in gutters, sewers, and drains. The accumulation clogs water drainage pathways and exacerbates flood conditions in low-lying neighbourhoods (Essien, 2014). The blocking of the gutters and drains causes flooding whenever it rains because the rainwater cannot get access to flow and the stagnation of the rainwater also provide a breeding place for mosquitoes, which can cause malaria to the people. For many low-income neighbourhoods also, flooded drains ultimately lead to increased risk of exposure to untreated sewage, animal waste, and runoff from urban agriculture.

The consumption of sachet water also poses a considerable health threat to the many Ghanaians that depend on it as numerous researchers have raised concerns about the quality of sachet water. Studies conducted in various Ghanaian cities (Accra, Tema, Kumasi, Cape Coast) found that mineral levels are often within WHO guidelines for potable water among randomly selected sachets, but many exceeds acceptable levels of fecal coliforms, total coliforms and bacteria (Obiri-Danso et al., 2003; Dodoo et al., 2006; Ampofo et al., 2007; Kwakye-Nuako et al., 2007; Okioga, 2007; Addo et al., 2009; Ackah et al., 2012; Osei et al., 2013). Consumption of contaminated sachet water was identified as one of the major causes of a cholera outbreak in the country in 2011, an epidemic due to the unfortunate quality plight of the industry (Ackah-Arthur, 2011). However, sachet water use is also associated with higher levels of self-reported overall health in women, and lower likelihood of diarrhoea in children (Stoler et al., 2012). According to Addei (2016), sachet water quality has improved considerably in the last few years, as registered producers are producing sachet water often to higher (and more reliable) physiochemical and microbiological standards. These registered producers are subject to sanitation training and provide lab-verified water samples among other obligations to the Ghana Food and Drugs Authority (FDA), yet the FDA estimates that there are over twice as many unregistered sachet water producers than registered ones (Ackah et al., 2012; Stoler et al., 2013; Addei, 2016) where lies the threat. In summary, while most of the literature reviewed is quick to praise sachet water's role in narrowing the potable water access gap in the nation, the scrutiny on sachet water quality and environmental sustainability ultimately problematizes the industry.

\section{Producer Responsibility and Environmental Management}

There are no current statistics on the quantity of sachet water waste collected in Ghana, yet it is evident that a greater portion of plastic waste generated in Ghana can be attributed to the sachet waste from the sachet and packaged water industry. As stated earlier, despite the significance of sachet water production to Ghana's economy (Attah, 2016) and to improve the accessibility to potable drinking water, its contribution to plastic waste generation and management problems in the country cannot be overlooked. This has resulted in threats by some metropolitan, municipal and district assemblies and the Central Government to impose levies on the production of sachet water or to ban its production completely, a proposal that resurfaces 
annually in Ghanaian policy circles concerned with waste management, and has precedent in sub-Saharan Africa (Simpson, 2007; Stoler et al., 2014). These threats if carried out could increase the cost of production of sachet water (Stoler et al., 2014) and/or worsen the unemployment situation in the country, as the industry is estimated to employ more than two million people directly and indirectly (Suleman, 2014).

Realizing the impact of these threats, sachet water producers in the country have been engaging with the authorities on how to resolve the plastic/sachet waste situation. Hence the National Association of Sachet Water Producers (NASWAP) in this regard, engages in activities such as contributing money to assist in plastic waste management (Ghanaweb, 2005), donation of bins in public places to facilitate the disposal of sachet wastes (GNA, 2012), assisting in the transfer of technology to members, facilitating training courses in book-keeping and environmental education. A study done in Wa municipality by Kavaarpuo and Wulifan in 2013 showed that the 14 sachet water producers they observed were already engaged in some form of producer responsibility as they had initiated some approaches to contribute to solving the downstream environmental menace of their products. They observed $57.14 \%$ of the producers retrieve empty sachets either from retailers and/or by engaging the services of scavengers (waste pickers) who collect the littered sachets in the Wa municipality for a fee (Kavaarpuo and Wulifan, 2013). Therefore, it is evident that without any mandatory requirement, the industry has been making efforts to help manage the environmental impact of sachet water use on Ghanaian environment and with the right policy instruments, the nation can benefit fully.

\section{Eco-efficiency and Implications for the sachet water industry}

In the field of eco-efficiency, the eco-efficient services are generally defined as product-service systems that provide the greatest value added for the customer with a considerably smaller environmental damage (Bartolomeo et al., 2003). Eco-efficient services are considered as the route to sustainable development (Anttonen, 2012). The general idea of eco-efficient services can be divided into three types of conceptual services approaches; product-based, use-oriented, and result-oriented services (Anttonen et al., 2013). Result-oriented services aim to solve customer's specified and on-going needs more eco-efficiently while product-based services are extensions of product ownership with supporting services that require regular maintenance and use-oriented services can include rental and leasing or repair, maintenance, and take-back services (Bartolomeo et al., 2003; Anttonen et al., 2013)

The sachet water industry is faced with many challenges such as compliance with environmental legislation, water wastage, energy demand and cost, proper disposal of the product after use. With the recent increase in the sachet water industry in Ghana, introducing eco-efficiency principles in their operations will help decrease their impacts on the Ghanaian environment and stop the pushback from the state on the industry because of these environmental impacts. Even though the concept of eco-efficiency is criticised as focussed on improving the manufacture of products and less on their consumption, new innovative concepts like use-oriented services can help industries like the sachet water industry help manage the environmental impacts of their products after use. As the pace of waste management infrastructure is too slow to keep up with the rise of sachet water use, the waste generated is ultimately greater cause for public health and municipal management concern (Stoler, 2012). This is one area where the industry can do more to minimize the environmental impact.

According to World Business Council on Sustainable Development (WBCSD), there are seven elements or characteristics of eco-efficiency that provides a guide to help business to become more eco-efficient (Schmidheiny, 1992; Côté et al., 2005);

i) Reduce material intensity.

ii) Reduce energy intensity.

iii) Reduce dispersion of toxic substances.

iv) Enhance recyclability.

v) Maximise use of renewable resources.

vi) Extend product durability.

vii) Increase service intensity.

To become eco-efficient, the sachet water industry can incorporate the above principles, with the help of industry associations like the NASWAP, into their production processes and must also focus on strategies and methods like cleaner production, total quality management, pollution prevention, source reduction, reuse, and recycling. As plastic recycling activities is gaining much attention in the country and some plastic and recycle companies are beginning to pay cash for large numbers of empty sachets, motivating some households to save their sachets (Little, 2015), this is another area where the industry can get involved by instituting take-back schemes and educating consumers not to litter.

\section{Policy support for eco-efficiency in sachet water industry}

Though it is important the Government understands and speaks the language of business when setting and implementing sustainable development policies, however, this does not mean conforming to all business demands. It does mean recognizing that companies, small business, in particular, are often not familiar with the terms used by policy-makers and experts and/or interpret them in different ways. The Sachet water industries cannot achieve eco-efficiency alone as sustainability in the sector requires going beyond the internal actions of individual companies. It requires close cooperation among the stakeholders. It needs society 
to create an enabling framework which allows individual companies and whole markets to become more eco-efficient. The Government of Ghana has an important role to play in creating these conditions.

As shown in Tab. I below, there are a few policy instruments that the government of Ghana can employ especially with regards to minimizing, reuse and recycling sachet water waste through extended producer responsibility (EPR) in the sachet water industry to encourage eco-efficiency.

Companies in the sachet water industry in Ghana can implement eco-efficiency along the entire value chain of their product, not just within the physical boundaries of the plant. As the main harmful effects on the environment with which they are associated with mostly occur outside their fences, mainly downstream in the product use or disposal phases, eco-efficiency can be achieved through these key approaches:

- Minimizing their Energy Use

- Minimize Water Wasting

- Undertake AND encouraging recycling of sachet water waste through Extended producer responsibility
The sachet water producers can incorporate the aspects of eco-efficiency that make an indispensable strategic element in business as shown in Fig. 1 below.

As shown in Fig. 1, the producers of sachet water can be encouraged to achieve eco-efficiency in the industry through these four main areas;

- Waste recycling: where the producers themselves undertake recycling initiatives or encourage the proper disposal of their products after use by customers through education and incentives

- Optimised process: Where they consider their impacts by optimising energy and water use and by employing Environmental management system (EMS)

- Innovations: Where the industry invest in much more environmental friendly technology and products

- Networking: Even though there are some associations and groups in the industry, there needs to a nationwide industry network that can help improve the standards of production through the sharing of information and resources.

I: Policy instruments to encourage eco-efficient in the industry

\begin{tabular}{lr}
\hline \multicolumn{1}{c}{ Category } & Examples \\
\hline Regulatory instruments & $\begin{array}{r}\text { Take-back programs (mandatory or voluntary), including the provision of } \\
\text { infrastructure; reuse and recycling targets; minimum product standards; } \\
\text { prohibitions of certain hazardous materials or products; disposal bans; mandated } \\
\text { recovery/recycling obligations }\end{array}$ \\
Economic instruments & $\begin{array}{r}\text { Product taxes, input/material levies, virgin material taxes, collection fees, disposal fees, } \\
\text { deposit-refund schemes, subsidies, tax/subsidy combinations }\end{array}$ \\
Information instruments & $\begin{array}{r}\text { Environmental reports; environmental labelling; information provision to consumers, } \\
\text { collectors, recyclers, etc. through education and awareness-raising campaigns }\end{array}$ \\
\hline
\end{tabular}

Source: adapted from (Widmer et al., 2005; Nnorom and Osibanjo, 2008; Nahman, 2009).

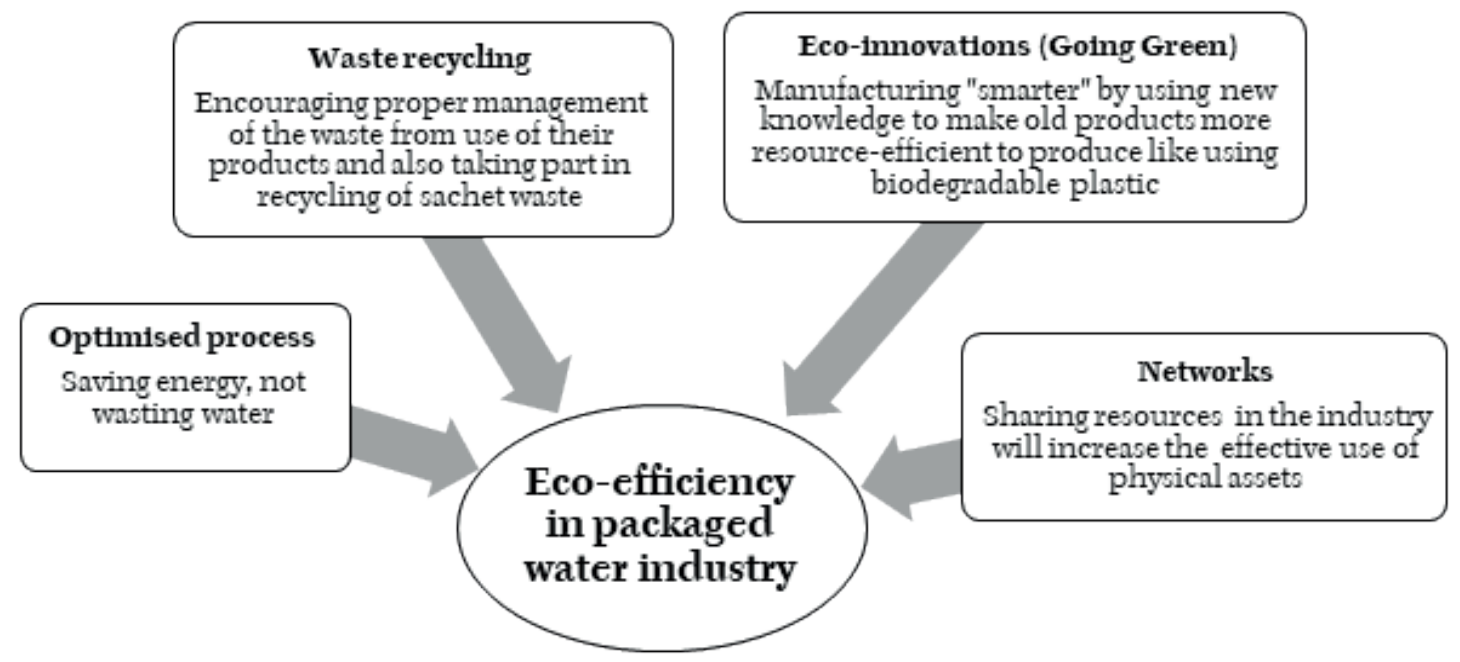

1: The case of Eco-efficiency for sachet water industry (SWI) in Ghana

Source: Adapted from WBCSD learning module on eco-efficiency n.d. 


\section{CONCLUSION}

Sustainable development is a development that meets the needs of the present, without compromising the ability of future generations to meet their needs (WCED, 1987) and one of the basic human needs of present and likewise, future generation is access to safe drinking water. Though the sachet water industry in Ghana greatly enhances the accessibility to this basic human need and also generates employment opportunities for many Ghanaians, it is important to pay particular attention to the impact of the industry on the Ghanaian natural environment. To resolve the problem of empty sachet water bags being improperly disposed of, littering the streets and clogging the gutters throughout cities in Ghana, causing visual offensive environment and so many related environmental issues will require the attention of the industry, consumers and the government. The application of eco-efficiency thinking has been increasing among various national economies and SMEs enterprises. Eco-efficiency is about increasing value added while decreasing environmental impacts. The industrial sector in Ghana can be improved considerably in terms of their environmental impacts by adopting the concept of eco-efficiency.

As the greatest environmental impact of the sachet water industry occurs at the end of their product lifecycle, a well-managed recovery program for sachet water waste in Ghana based on extended producer and consumer responsibilities, combined with improvement in national waste management conditions will be ideal. It also is necessary that one looks wider and beyond to include all the other contributors to plastic waste menace as a sustainable plastic waste retrieval mechanism is formulated. An eco-efficient framework with effective recovery program can result in significant improvement in sachet and plastic recycling in the country and this can translate to cost savings for the producers. The reality of the situation is that the collapse of the sachet and bottled water companies would send massive shockwaves through the economy. Hence a sustainable sachet/packaged water industry will translate to socio-economic growth and environmental sustainability in Ghana.

In conclusion, there are many reasons for adopting eco-efficiency in the packaged water industry, including:

- reducing operating costs and improve profitability

- reducing energy, water supply, and solid waste costs

- reducing water wastage

- contribute to developing solid waste minimization plans in Ghana

- creating an 'environmentally friendly' image and gain a competitive edge,

- improving relations with state environmental regulators and ensure compliance with environmental regulations and adopting an environmental management system.

Even though there are some relevant critiques against eco-efficiency, it is an important step towards sustainable production and consumption. It is extremely important that SMEs like the majority of sachet water producers, which are often overlooked for such concepts takes responsibility. There need to be further studies in finding ways to convince the hundreds of thousands of SMEs by making eco-efficiency a priority in their daily operations, which can lead to better economic and environmental performance while satisfying legal requirements. Further studies are needed in regard to how to adopt and adapt such relevant tools to local conditions and provide incentives and other support mechanisms and programs that promote eco-efficiency to micro and small businesses.

Acknowledgements

Our study was financed as part of IGA research project No. SP3160861/ 2101 / 311.

\section{REFERENCES}

ACKAH, M., ANIM, A. K., GYAMFI, E. T., ACQUAH, J., NYARKO, E. S., KPATTAH, L., BROWN, S. E., HANSON, J. E., FIANKO, J. R. and ZAKARIA, N., 2012. Assessment of the quality of sachet water consumed in urban townships of Ghana using physicochemical indicators: A preliminary study. Advances in Applied Science Research, 3(4): 2120-2127.

ACKAH-ARTHUR, E. 2011. Total quality management (TQM) as a strategy to improve the performance of sachet/bottle water industry in Ghana. Ph.D. Thesis. Kumasi: Institute of Distance Learning, KNUST.

ADDEI, E., 2016. The wealth of plastic recycling: A comparison between plastic recycling companies in Accra and one in Gauteng, South Africa, for improvement purposes. Ph.D. Thesis. Department of Business Administration. Asheshi University, Ghana.

ADDO, K. K., MENSAH, G. I., DONKOR, B., BONSU, C. and AKYEH, M. L., 2009. Bacteriological quality of bottled water sold on the Ghanaian market. African Journal of Food, Agriculture, Nutrition and Development, 9(6): 1378-1387. 
ADJEI, S. A., 2016. Access to water and financial implications of groundwater development in Dodowa, Ghana. Ph.D. Thesis. Kumasi. Ghana: KNUST. Available at: http://ir.knust.edu. gh/bitstream/123456789/9037/1/ADJEI\%20SETH\%20ALLABO.pdf [Accessed: 2018, Februrary 20].

AMPOFO, J. A., ANDOH, A., TETTEH, W. and BELLO, M. 2007. Microbiological quality and health risks of packaged water produced in southern Ghana. J. Appl. Sci. Technol., 12(1-2): 88-97.

ANTTONEN, M., 2012. Eco-efficient services as a route towards sustainable development: between the traditional and the radical. Ph.D. Thesis. No. 181. Corporate Responsibility Research Group, Department of Management and International Business, School of Business, Aalto University.

ANTTONEN, M., HALME, M., HOUTBECKERS, E. and NURKKA, J., 2013. The other side of sustainable innovation: is there a demand for innovative services?. Journal of cleaner production, 45: 89-103.

ATTAH,M.2016.Issomeonelistening to the sachetwaterproducers? Myjoyonline.com.Availableat:https://www. myjoyonline.com/opinion/2016/March-21st/is-someone-listening-to-the-sachet-water-producers.php [Accessed: 2018, February 20].

BARTOLOMEO, M., DAL MASO, D., DE JONG, P., EDER, P., GROENEWEGEN, P., HOPKINSON, P., JAMES, P., NIJHUIS, L., ÖRNINGE, M., SCHOLL, G., SLOB, A. and ZARING, O., 2003. Eco-efficient services-what are they, how do they benefit customers and the environment and how likely are they to develop and be extensively utilized. Journal of Cleaner Production, 11: 829-837.

BONSU, A. 2013. Sachet water production - A thriving business with health implications. Graphic Online Business News. Available at: https://www.graphic.com. gh/business/business-news/sachet-water-production-a-thriving-business-with-health-implications. html?template $=$ grabbc5 5 and is_preview=on [Accessed: 2018, February 20].

CÔTÉ, R., BOOTH, A., and LOUIS, B. 2006. Eco-efficiency and SMEs in Nova Scotia, Canada. Journal of Cleaner Production, 14(6-7): 542-550.

DODOO, D. K., QUAGRAINE, E. K., OKAI-SAM, F., KAMBO, D. J. and HEADLEY, J. V. 2006. Quality of "sachet" waters in the Cape Coast municipality of Ghana. Journal of Environmental Science and Health Part A, 4l(3): 329-342

DZODZOMENYO, M., DOTSE-GBORGBORTSI, W., LAPWORTH, D., WARDROP, N. and WRIGHT, J. 2017. Geographic distribution of registered packaged water production in Ghana: implications for piped supplies, groundwater management, and product transportation. Water, 9(2): 142.

EIK, A. 1998. Eco-efficiency-state of the art. Available at: http://ntnu.diva-portal.org/smash/get/ diva2:122159/FULLTEXT01.pdf [Accessed: 2018, February 20].

ENDACOTT, R. 2005. Clinical research 4: qualitative data collection and analysis. Intensive and Critical Care Nursing, 21(2): 123-127.

FRANK, E. 2014. Plastic waste: a gargantuan environmental problem for Ghana. Ghanaweb.com. Available at: https:/www.ghanaweb.com//GhanaHomePage/features/ Plastic-waste-a-gagantuan-environmental-problem-for-Ghana-299666 [Accessed: 2018, February 20].

GADGIL, A. 1998. Drinking water in developing countries. Annual review of energy and the environment, 23(1): 253-286.

GHANA STANDARDS AUTHORITY. 2005. Water quality - specification for natural mineral water. Accra: GS 220: 2005; $p 9$.

GHANA STANDARDS AUTHORITY. 2009. Water quality - specification for drinking-water. Accra, p 23.

GHANA STATISTICAL SERVICE (GSS), GHANA HEALTH SERVICE (GHS), and ICF MACRO. 2009. Ghana Demographic and Health Survey 2008. Accra, Ghana: GSS, GHS, and ICF Macro. Available at: https://www. dhsprogram.com/pubs/pdf/FR221/FR221[13Aug2012].pdf [Accessed: 2018, February 20].

GHANA STATISTICAL SERVICE (GSS), GHANA HEALTH SERVICE (GHS), and ICF INTERNATIONAL. 2015. Ghana Demographic and Health Survey 2014. Rockville, Maryland, USA: GSS, GHS, and ICF International. Available at: https://dhsprogram.com/pubs/pdf/FR307/FR307.pdf [Accessed: 2018, February 20].

GHANA WATER COMPANY LIMITED (GWCL). 2018. Company Profile. GWCL. Available at: http://www. gwcl.com.gh/company_profile.html [Accessed: 2018, February 20].

GHANAWEB. 2016. 1,200 sachet water firms in Ghana. Ghana Web Business News. Available at: https://www. ghanaweb.com/GhanaHomePage/business/1-200-sachet-water-firms-in-Ghana-412833 [Accessed: 2018, February 20].

GOLAFSHANI, N., 2003. Understanding reliability and validity in qualitative research. The qualitative report, 8(4): 597-606.

HOEPFL, M. C. 1997. Choosing qualitative research: A primer for technology education researchers. Journal of Technology Education, 9(1): 47-63

HOPEWELL, M. and GRAHAM, J. 2014. Trends in access to water supply and sanitation in 31 major sub-Saharan African cities: an analysis of DHS data from 2000 to 2012. BMC Public Health, 14(1): 208.

IRIN. 2004. Ghana Government Declares Recycling War on Plastic Waste. UN Office for the Coordination of Humanitarian Affairs, Nairobi.

KAVAARPUO, G., WULIFAN, J. K. 2013. Extended producer responsibility - potentials for managing plastic waste in Ghana. Journal of Sustainable Development in Africa, 15(7):29-39 
KUSI, L. Y., AGBEBLEWU, S. and NYARKU, K. M., 2015. Challenges and Prospects Confronting Commercial Water Production and Distribution Industry: A Case Study of the Cape Coast Metropolis. International Journal of Management Sciences, 5(7): 544-555.

KWAKYE-NUAKO, G., BORKETEY, P. B., MENSAH-ATTIPOE, I., ASMAH, R. H. and AYEH-KUMI, P. F., 2007. Sachet drinking water in Accra: the potential threats of transmission of enteric pathogenic protozoan organisms. Ghana medical journal, 41(2): 62-67.

LITTLE, R. J. 2015. The State of Sachets: Ghana's Private Sector Solution to a Public Infrastructure Problem" (2015). Pitzer Senior Thesis. 62. Environmental Analysis. Pitzer College. Available at: http://scholarship.claremont. edu/pitzer_theses/62 [Accessed: 2018, February 20].

MAHAMA, A. M., ANAMAN, K. A. and OSEI-AKOTO, I. 2014. Factors influencing householders“ access to improved water in low-income urban areas of Accra, Ghana. Journal of water and health, 12(2): 318-331.

MINISTRY OF WATER RESOURCES, WORKS, AND HOUSING. 2010. Water and Sanitation Sector Performance Report. (WSSPR) Accra, Ghana. Available at: http://sanitationandwaterforall. org/wp-content/uploads/download-manager-files/Final_2010_Sector_Performance_Report[1].pdf [Accessed: 2018, February 20].

MORINVILLE, C. 2017. Sachet water: regulation and implications for access and equity in Accra, Ghana. Wiley Interdisciplinary Reviews: Water, 4(6): e1244.

MUSTAPHA, S. and ADAM, E. A. 1991. Discussion on Water Problems in Nigeria: Focus on Bauchi State. Natl. Water Res. Inst.

NAHMAN, A. 2009. Extended producer responsibility for packaging waste in South Africa: Current approaches and lessons learned. Resources, Conservation and Recycling (In press).

NNOROM, I. C. and OSIBANJO, O., 2008. Overview of electronic waste (e-waste) management practices and legislation, and their poor applications in the developing countries. Resources, conservation, and recycling, 52(6): 843-858.

OBIRI-DANSO, K., OKORE-HANSON, A. and JONES, K. 2003. The microbiological quality of drinking water sold on the streets in Kumasi, Ghana. Letters in Applied Microbiology, 37(4): 334-339.

OKIOGA, T. T. I. 2007. Water quality and business aspects of sachet-vended water in Tamale, Ghana. Ph.D. Thesis. Dept. of Civil and Environmental Engineering, Massachusetts Institute of Technology.

OKOGIA, T. 2007. Water Quality and Business Aspects of Sachet-Vended Water in Tamale, Ghana. MSc Thesis. Civil, and Environmental Engineering, Massachusetts Institute of Technology.

OSEI, A. S., NEWMAN, M. J., MINGLE, J. A. A., AYEH-KUMI, P. F. and KWASI, M. O. 2013. Microbiological quality of packaged water sold in Accra, Ghana. Food Control, 31(1): 172-175.

SCHALTEGGER,S.1996. Eco-efficiency ofLCA.Thenecessity of a site-specific approach.In:SCHALTEGGER, S. (Ed.). Life Cycle Assessment (LCA) - Quo vadis. Basel: Birkhäuser, pp.133-149.

SCHMIDHEINY, S. 1992. Changing course: A global business perspective on development and the environment. Vol. 1. MIT Press.

SILVERMAN, D. 2010. Doing qualitative research. $3^{\text {rd }}$ Edition. London: Sage Publications.

SIMPSON, S. 2007. Clogged by Plastic Bags, Africa Begins Banning them. The Christian Science Monitor. Available: https://www.csmonitor.com/2007/1130/p01s04-woaf.html [Accessed: 2018, February 20].

STOLER, J. 2013. The sachet water phenomenon in Accra: socioeconomic, environmental, and public health implications for water security. In: Spatial Inequalities: Health, Poverty, and Place in Accra, Ghana. GeoJournal Library 110, Springer Science and Business Media Dordrecht, pp. 181-190.

STOLER, J., FINK, G., WEEKS, J. R., OTOO, R. A., AMPOFO, J. A. and HILL, A. G. 2012. When urban taps run dry: Sachet water consumption and health effects in low-income neighborhoods of Accra, Ghana. Health and Place, 18(2): 250-262.

STOLER, J., TUTU, R. A. and WINSLOW, K. 2015. Piped water flows but sachet consumption grows: The paradoxical drinking water landscape of an urban slum in Ashaiman, Ghana. Habitat International, 47: 52-60.

STOLER, J., TUTU, R. A., AHMED, H., FRIMPONG, L. A. and BELLO, M. 2014. Sachet water quality and brand reputation in two low-income urban communities in Greater Accra, Ghana. The American journal of tropical medicine and hygiene, 90(2): 272-278.

STOLER, J.; WEEKS, J. R. and FINK, G. 2012. Sachet drinking water in Ghana's Accra-Tema metropolitan area: Past, present, and future. Journal of Water Sanitation and Hygiene for Development, 2: 223-240.

STRAUSS, A. and CORBIN, J. 1990. Basics of qualitative research. Vol. 15. Newbury Park, CA: Sage. Vancouver

SULEIMAN, M. 2014. 4 million jobs created in sachet water trade. Graphic Online, Business News. Available at: http://graphic.com.gh/business/business-news/29851-4-million-jobs-created-in-sachet-water-trade. html\#sthash.ibWqMMOc.dpuf [Accessed: 2018, February 20].

TUKKER, A. and TISCHNER, U. 2006. Product-services as a research field: past, present, and future. Reflections from a decade of research. Journal of Cleaner Production, 14(17): 1552-1556.

VEDACHALAM, S., MACDONALD, L. H., OMOLUABI, E., OLAOLORUN, F., OTUPIRI, E. and SCHWAB, K. J. 2017. The role of packaged water in meeting global targets on improved water access. Journal of Water Sanitation and Hygiene for Development, 7(3):369-377. 
WARDROP, N. A., DZODZOMENYO, M., ARYEETEY, G., HILL, A. G., BAIN, R. E. and WRIGHT, J. 2017. Estimation of packaged water consumption and associated plastic waste production from household budget surveys. Environmental Research Letters, 12:074029.

WCED, UN. 1988. "Our common future.". World Commission on Environment and Development. Oxford University Press.

WIDMER, R., OSWALD-KRAPF, H., SINHA-KHETRIWAL, D., SCHNELLMANN, M. and BÖNI, H. 2005. Global perspectives on e-waste. Environmental impact assessment review, 25 (5): 436-458.

Ebo Tawiah Quartey: ebo.quartey@mendelu.cz Samuel Antwi Darkwah: darkwah@mendelu.cz 